\title{
Optimising residential respite care in nursing homes: current problems, and solutions for a better future
}

Melissa Willoughby, $\mathrm{BA}^{1}$, Joseph Elias Ibrahim, $\mathrm{PhD}^{1}$, Noha Ferrah, $\mathrm{MD}^{1}$, Lyndal Bugeja, $\mathrm{PhD}^{1}$

${ }^{1}$ Health Law and Ageing Research Unit Department of Forensic Medicine, Monash

University, 65 Kavanagh Street Southbank Victoria 3006 Australia

\section{Corresponding author}

Joseph E Ibrahim, Department of Forensic Medicine, Monash University, 65 Kavanagh

Street, Southbank Victoria 3006 Australia, phone: +61 39684 4364, fax: +61 39684 4475,

email: joseph.ibrahim@monash.edu

\section{Running head}

Does residential respite care increase mortality?

\section{Funding}

This work was supported by Commonwealth Department of Social Services; Department of Health and Human Services, Aged Care Branch, Victoria, Australia; and the Department of Forensic Medicine, Monash University. None of the funders influenced the design, methods, subject recruitment, data collections, analysis and preparation of paper.

\section{Disclaimers}

The views and opinions expressed in this article are those of the authors and do not necessarily reflect the official policy or position of any agency or departments of the Australian Federal Government, the State Government of Victoria, Monash University, the Victorian Institute of Forensic Medicine or the Coroners Court of Victoria.

Declaration of Conflicting Interests

This is the author manuscript accepted for publication and has undergone full peer review but has not been through the copyediting, typesetting, pagination and proofreading process, which may lead to differences between this version and the Version of Record. Please cite this article as doi: $10.1111 /$ opn.12180

This article is protected by copyright. All rights reserved 
The authors are affiliated and employed by the Department of Forensic Medicine, Monash University, which is also a funding source. The authors have no other potential financial or personal interests that may constitute a source of bias.

\section{Ethical approval}

Ethical approval was not required as the research is based on published literature.

\section{Submission declaration}

This material has not been previously published and is not under consideration for any other publication.

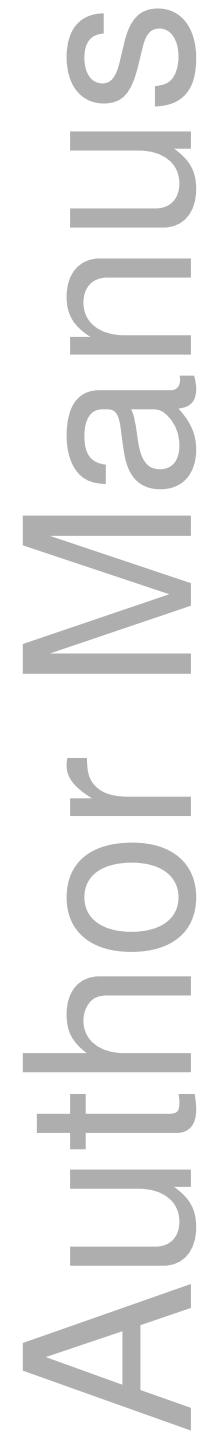




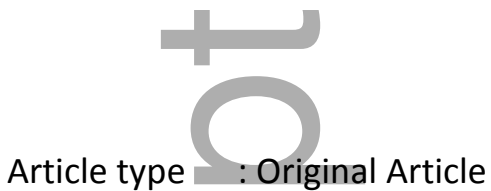

Article type : Original Article

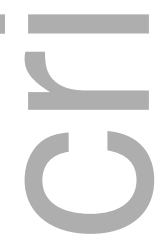

Optimising residential respite care in nursing homes: current problems, and solutions for a better future

\section{ABSTRACT}

Aim: To examine whether residential respite care increases the risk of harm to older people and suggest directions for future research and policy.

Background: Respite care is a vital part of the age care system that supports dependent older people and their care-givers to continue residing in the community. There is little research determining whether an older person experiences harm from residential respite.

Methods: This commentary considered conceptual research and existing empirical evidence to determine whether the risk of death was greater during residential respite care for older people.

Results: Evidence on the mortality in contemporary respite care is extremely limited with the majority of studies published almost 20 years ago and focussing on planned respite admissions. The evidence available has limitations in design, lacks comparison groups and key variables relevant to outcome and risk stratification. Nonetheless, it provides a theoretical basis supporting that the potential for harm and mortality may be increased during a residential respite care admission.

Conclusions: The question of whether residential respite care presents significant risks to older people remains unanswered. Substantial changes in practice since the last century 
make the existing empirical evidence redundant. However, there is much to learn by reflecting on omissions of important details from these studies.

Implications for practice: A full and objective understanding of the harm associated with residential respite care for older people requires re-opening and re-examining this area with robust research. Informed professional nursing practice and policy requires an empirical evidence basis to residential respite care.

Key words: Respite, mortality, death, adverse events

\section{SUMMARY STATEMENT OF IMPLICATIONS FOR PRACTICE}

\section{What does this research add to existing knowledge in gerontology?}

- Our current knowledge of mortality as an outcome in contemporary residential respite care (RRC) is limited and appears to be considered as non-existent.

- We found the published research on mortality in RRC is out dated, with limitations in design, and lacks comparison groups and key variables relevant to outcome and risk stratification.

- The potential risks of contemporary residential respite care and practice remain to be elucidated.

\section{What are the implications of this new knowledge for nursing care with older people?}

- There is insufficient empirical information to develop contemporary evidence based nursing practice for residential respite care.

- Nurses and aged care practitioners need to re-examine whether RRC is associated with adverse outcomes, and if this is the case, to determine which residents are at risk and how to prevent harm.

- However, principles derived from the existing research could be used to inform concepts aiming to improve transitions of care.

- Evidence based nursing staff practices have the potential to improve the quality and safety of respite care for residents. 


\section{How could the findings be used to influence policy or practice or research or education?}

- The need for RCC is projected to increase exponentially and there is substantial evidence on the benefits of RCC.

- To continue to provide and possibly expand RCC, the first step is to determine whether this is safe service for older people.

- There is a need for more professional advocacy to promote work that investigates whether harm and excess mortality occurs in RRC and to ensure there is a strong evidence base to RRC practice.

\section{INTRODUCTION}

Increasingly, older people in high income (Organisation for Economic Co-operation and Development (OECD)) countries are staying at home longer instead of moving into permanent care (Organisation for Economic Co-operation and Development, 2005). Respite care, which is widely used in those countries (Colombo, Llena-Nozal, Mercier, \& Tjadens, 2011), partly enables this. The demand for respite is high with an estimated 34.2 million adults caring for a dependent older person aged 50 years and older in the Unites States (US) (National Alliance for caregiving, 2015). Other frequently cited benefits of respite care include a reduction in care-giver burden and enable the dependent older person reside in the community for longer (Lee \& Cameron, 2004) and in government spending (International Alliance of Carer Organizations, 2015; Neville, Beattie, Fielding, \& MacAndrew, 2015; Pickard, 2004).

Respite care refers to a wide variety of services providing temporary care by people other than the usual care-giver to the dependent older person, in their home, day-care or residential institutions (Australian Institute of Health and Welfare, 2015). Here, we focus on residential respite care $(R R C)$, which entails the dependent older person temporarily residing in a nursing home for a short period of time, usually two weeks (Australian Institute of Health and Welfare, 2015). RRC can be arranged as a planned booking or an emergency 
admission, such as when a care-giver has suddenly fallen ill (Australian Institute of Health and Welfare, 2015).

Akin to other care transitions, admission to RCC has inherent theoretical risks (Ferrah, Ibrahim, Kipsaina, \& Bugeja, 2017). Nurses are the central health profession in the delivery of RRC, through their vital role in identifying the need for respite care, and in the management, planning and delivery of care services (Australian College of Nursing, 2016). They are therefore in a unique position to assess and guarantee the safety of older dependent people during admission to RCC. As the health and care needs of the aging population become increasingly complex, so do the competencies required of nurses to achieve this (Australian College of Nursing, 2016).

However, notwithstanding the widely held beliefs in the merits of RRC, corresponding evidence-based nursing practice is limited. It is currently unknown what effect if any, RRC has on the mortality and morbidity of older persons using this service. RRC residents and their care-givers expect and are entitled to safe and effective evidence-based care. It is therefore imperative for nursing practice to be based on an accurate understanding of the risk of mortality in RRC, in order to continue to improve this important part of aged care services.

This commentary therefore examines whether admission to RRC increases the risk of harm to older people and suggest directions for future research, policy and practice. RCC involves multiple transfers of care within a short period. In light of the well-documented heightened risk of mortality during other types of transitions of care to hospitals and permanent residential care institutions (Doupe, Brownell, St. John, Strang, et al., 2011, Segall, Bonifacio, Schroeder, Barbeito, et al., 2012), we postulated that RRC could also be associated with an increased risk of mortality. While the characteristics of people transitioning to hospitals and permanent nursing homes are likely to differ, the processes involved such as admission and discharge have converging aspects.

\section{Empirical evidence investigating deaths in RRC}

We conducted a systematic literature review of published studies examining the deaths of older people during RRC (see Appendix 1). Remarkably, only twelve studies examining 
deaths of older people in RRC have ever been published (see Appendix 2 and 3) (Rai, Bielawska, Murphy, Wright, et al., 1986; Harper, McDowell, Turner, \& Sharma, 1988; Dunstan, 1989; McCaffrey, Gilmore, \& Beringer, 1989; Patterson \& Compton, 1989; Selley \& Campbell 1989; Howarth, Clarke, Bayliss, Whitfield, et al., 1990; O'Mahony, Hyland \& Twomey, 1990; Chang, Karuza, Katz, \& Klingensmith, 1992; Primrose \& Primrose 1992; Cassidy \& Farquhar, 1995; Choi \& Liu, 1998). Most studies were conducted over 15 years ago and published over a 12-year period, predominantly from the United Kingdom.

Mortality ranged from $1 \%(n=129, n=1)$ (Harper, McDowell, Turner, \& Sharma, 1988; Choi \& Liu, 1998) to $35 \%$ ( $n=15$ ) (Rai, Bielawska et al. 1986) of RRC residents. An initial study (Rai, Bielawska, Murphy, Wright, et al., 1986) raised controversy by reporting an excess mortality in RRC with a significant difference compared to other care settings. This was subsequently refuted by multiple studies finding that admission to RRC was not associated with an increased risk of mortality (Dunstan, 1989; McCaffrey, Gilmore, \& Beringer, 1989; Selley \& Campbell 1989; Chang, Karuza, Katz, \& Klingensmith, 1992; Cassidy \& Farquhar, 1995).

However, many of these studies (Dunstan, 1989; McCaffrey, Gilmore, \& Beringer, 1989; Selley \& Campbell 1989; Cassidy \& Farquhar, 1995) only examined planned admissions, whereas the initial study (Rai, Bielawska, Murphy, Wright, et al., 1986) examined both planned and emergent admissions. Higher mortality was greater in emergent admissions $(35 \%, n=15)$ than planned admissions (13\%, n=9) (Rai, Bielawska, Murphy, Wright, et al., 1986).

Only four studies (Rai, Bielawska, Murphy, Wright, et al., 1986; McCaffrey, Gilmore, \& Beringer, 1989; Patterson \& Compton, 1989; Howarth, Clarke, Bayliss, Whitfield, et al., 1990) reported the causes of death, and surprisingly, not a single death was due to an injury, such as a fall. All deaths were deemed natural with most being due to bronchopneumonia and heart disease. Studies did not specify whether the deaths were a premature (iatrogenic or injury-related) or a natural cause death.

Possible factors that may impact the risk of mortality for RRC residents, such as indications for RRC (care-giver holiday or illness, introduction to residential care before moving to permanent care), health characteristics of individuals (physical, cognitive, mental health, 
frailty), characteristics of care-givers (age, health, relationship) and RRC facilities (size, general or speciality service, environmental design) were not reported.

As reassuring as these findings may appear, it is important to recognise that these studies were published last century, and are unlikely to be applicable to current nursing practices and/or the population using these services. The needs of this population today are more diverse and complex, owing to the rise in chronic disease and neurodegenerative conditions (Productivity Commission, 2008).

\section{Current challenges to understanding mortality in RRC}

Our current knowledge of mortality as an outcome in contemporary RRC is at best limited, at worst non-existent. The published research has limitations in design, lacks comparison groups and omits a range of key variables relevant to outcome and risk stratification. For example, many studies did not report the cause of death and so it is not possible to determine if deaths were preventable. These are important gaps in knowledge with profound implications for nurses and aged care practitioners and providers.

Similarly, the lack of specific detail about potential contributors to adverse outcomes and/or death, such as level of functioning, dementia, co-morbid conditions and frailty of residents, precludes us from determining whether the older person who died would have had the same outcome in their own home.

A further question is whether the structure and process of receiving RRC was a potential contributing factor. For example, a medication error that occurs due to a failure in a handover process during respite may not have occurred in the person's community dwelling. Another potential confounding factor is whether RRC was planned or unplanned and whether it was emergent because of a change in the status of the carer or the recipient. The majority of studies only examined planned admissions, yet unplanned and/or emergent RRC may have different effects on the risk of harm and mortality.

A major limitation of the studies is that they were published almost 20 years ago bringing into question their generalisability to contemporary RRC. It is unclear why this research topic has disappeared from the academic literature. Perhaps the expected benefits and anecdotal experiences of RRC as viewed by clinicians and care-givers have led to unfounded 
and biased assumptions on the safety of RRC. Assumptions about the safety and benefits of respite may be misplaced, as with other established practices that have been proven to be ineffective and even hazardous when reassessed. Prasad and colleagues demonstrated a substantial proportion of accepted practice is ineffective and even hazardous when they reviewed a decade of published medical practices (Prasad, Vandross, Toomey, Cheung, et al., 2013). They described 146 medical practices that were once accepted but now contraindicated including routine hormone therapy in postmenopausal women and, use of antibiotic therapy for asymptomatic bacteriuria.

\section{What should we do next?}

Changes to policy and practices in RCC are challenging with the paucity of empirical evidence. Further research is critically needed to ascertain the occurrence and extent of harm in RRC (Box 1). The delivery of RRC must be driven by sound, empirical rather than anecdotal evidence. There is a need for more professional advocacy from nurses, aged care practitioners and researchers to promote evidence-based practice in this area.

Nurses have a responsibility to ensure their practice and skills have evidence-based frameworks for respite care and are congruent with current standards established by regulatory bodies (Nursing and Midwifery Board of Australia, 2016). This entails determining whether RRC is associated with adverse outcomes, and if this is the case how to prevent harm and which residents are most at risk.

First a review of the most hazardous periods, including admission and discharges processes is essential: how residents are orientated on arrival, how information is gathered on admission and discharge and follow-up. "Is the same standard of practice applied to RRC clients as it is for permanent residents and, older patients who are admitted and discharged from acute care settings? And if not why not?".

Second, rigorous study design is required to elucidate whether RRC residents who died are different to those who survived, considering the multiple variables that may impact adverse outcomes associated with RRC (Table 1). For example, sicker, frailer RRC residents who can no longer be supported at home may be more likely to experience an adverse event. This situation could lead to an increase of mortality that is unrelated to the care delivered in 
RRC. These questions could be investigated using existing large databases (for example, Medicare data), descriptive studies, and prospective, controlled, longitudinal studies to determine multiple outcomes of RRC in a range of settings (aged care, palliative care alone and in combination), and including appropriate selection of comparison or control groups. Ideally three distinct populations should be enrolled-community dwellers who do use RRC; community dwellers who do not access RRC and; permanent residents.

Last, future studies should examine and report the causes of death of RRC residents and consider whether these were due to natural causes, or were premature and/or preventable. There are numerous techniques for this in health care that could be adapted to nursing home settings (Hogan, Healey, Neale, Thomson, et al., 2012).

Further, studies will need to ensure appropriate selection of comparison or control groups. Ideally three distinct populations should be enrolled-community dwellers who do use RRC; community dwellers who do not access RRC and; permanent residents.

\section{Conclusion}

There is a dearth of empirical evidence examining mortality in contemporary RRC. Only twelve studies have ever been conducted, all of which were published almost two decades ago and most lacking scientific rigor. If we are to have a full and objective understanding of the benefits and harms associated with RRC then this topic must be re-opened and reexamined. We cannot rely on outdated research, anecdotes or assumptions. This is the opportunity for nurses to take leadership to ensure that this vital service is delivered while preserving the safety of the older dependent people who crucially rely on it to continue to live in the community.

\section{REFERENCES}

Australian College of Nursing. (2016). The role of registered nurses in residential aged care facilities.Retrieved from https://www.acn.edu.au/sites/.../the role of the $\mathrm{rn}$ in residential aged care.pdf (accessed August, 2017) 
Australian Institute of Health and Welfare. (2015). Residential aged care and Home Care 201314.Retrieved from http://www.aihw.gov.au/aged-care/residential-and-home-care-2013$\underline{14 / \# t o c}$ (accessed March 3, 2017)

Campbell, J. (2008). Falls in older people. British Medical Journal, 337(a2320), 1247-1248. doi: $10.1136 /$ bmj.a2320

Cassidy, T., \& Farquhar, D. (1995). The characteristics of respite patients. Health Bulletin, 53(1), 1319.

Chang, J., Karuza, J., Katz, P., \& Klingensmith, K. (1992). Patient outcomes in hospital-based respite: a study of potential risks and benefits. The Journal of the American Board of Family Practice, 5(5), 475-481. doi: 10.3122/jabfm.5.5.475

Choi, C., \& Liu, Z. (1998). The use of nursing homes and hostels for respite care. Australasian Journal on Ageing, 17(2), 76-80. doi: 10.1111/j.1741-6612.1998.tb00038.x

Colombo, F., Llena-Nozal, A., Mercier, J., \& Tjadens, F. (2011). Policies to Support Family Carers Help wanted? Providing and Paying for Long-Term Care. Paris: OECD Publishing.

Cooper, A., Edwards, A., Williams, H., Evans, H., Avery, A., Hibbert, P., Makeham, M., Sheikh, A., Donaldson, L., \& Carson-Stevens, A. (2017). Sources of unsafe primary care for older adults: a mixed-methods analysis of patient safety incident reports. Age and Ageing. doi: https://doi.org/10.1093/ageing/afx044.

Doupe, M., Brownell, M., St. John, P., Strang, D., Chateau, D., \& Dik, N. (2011). Nursing Home Adverse Events: Further Insight into Highest Risk Periods. Journal of the American Medical Directors Association, 12(6), 467-474. doi: 10.1016/j.jamda.2011.02.002.

Dunstan, E. (1989). Why does regular relief care end? Age and Ageing, 18(3), 201-204. doi: https://doi.org/10.1093/ageing/18.3.201.

Ferrah, N., Ibrahim, J., Kipsaina, C., \& Bugeja, L. (2017). Death Following Recent Admission Into Nursing Home From Community Living: A Systematic Review Into the Transition Process. Journal of Aging Health, 2, 1-21. doi: 10.1177/0898264316686575.

Harper, N., McDowell, D., Turner, J., \& Sharma, A. (1988). Planned short-stay admission to a geriatric unit: one aspect of respite care. Age and Ageing, 17(3), 199-204. doi: https://doi.org/10.1093/ageing/17.3.199.

Hogan, H., Healey, F., Neale, G., Thomson, R., Vincent, C., \& Black, N. (2012). Preventable deaths due to problems in care in English acute hospitals: a retrospective case record review study. British Medical Journal Quality and Safety, 21, 737-745. doi: 10.1136/bmjqs-2012-001159.

This article is protected by copyright. All rights reserved 
Howarth, S., Clarke, C., Bayliss, R., Whitfield, A., Semmence, J., \& Healy, M. (1990). Mortality in elderly patients admitted for respite care. British Medical Journal, 300(6728), 844-847. doi: https://doi.org/10.1136/bmj.300.6728.844.

International Alliance of Carer Organizations. (2015). Global Carer Facts.Retrieved from http://www.internationalcarers.org/carer-facts/global-carer-stats/\# ednref14 (accessed December 10, 2016)

Lee, H., \& Cameron, M. (2004). Respite care for people with dementia and their carers. The Cochrane Library.

McCaffrey, P., Gilmore, D., \& Beringer, T. (1989). Mortality in the elderly during respite hospital care. The Ulster Medical Journal, 58(2), 131.

McCusker, J., Cole, M., Abrahamowicz, M., Han, L., Podoba, J., Ramman, \& Haddad, L. (2001). Environmental risk factors for delirium in hospitalized older people. Journal of the American Geriatrics Society, 49(10), 1327-1334. doi: 10.1046/j.1532-5415.2001.49260.x

Morley, J. (2013). Future Nursing Home Design: An Important Component in Enhancing Quality of Life. Journal of the American Medical Directors Association, 14(4), 227-229. doi: https://doi.org/10.1016/j.jamda.2013.01.018.

National Alliance for caregiving. (2015). Caregivers of Older Adults: A Focused Look at Those Caring for Someone Age 50+.Retrieved from http://www.caregiving.org/wpcontent/uploads/2015/05/2015 CaregivingintheUS Care-Recipients-Over-50 WEB.pdf (accessed March 28, 2017).

Neville, C., Beattie, E., Fielding, E., \& MacAndrew, M. (2015). Literature review: use of respite by carers of people with dementia. Health \& Social Care in the Community, 23(1), 51-63. doi: $10.1111 /$ hsc. 12095

Nursing and Midwifery Board of Australia. (2016). Registered Nurses Standards for Practice.Retrieved from http://www.nursingmidwiferyboard.gov.au/Codes-GuidelinesStatements/Professional-standards/registered-nurse-standards-for-practice.aspx (accessed August 29, 2017)

O'Mahony, M., Hyland, C., \& Twomey, C. (1990). Regular planned respite admissions to a geriatric unit. Irish Medical Journal, 83(3), 102-104.

Patterson, T., \& Compton, S. (1989). Mortality rates of patients admitted to a psychogeriatric assessment unit. The Ulster Medical Journal, 58(2), 134. doi: 10.1.1.275.3305.

This article is protected by copyright. All rights reserved 
Pickard, L. (2004). The effectiveness and cost-effectiveness of support and services to informal carers of older people: a review of the literature prepared for the Audit Commission. London, UK: Audit Commission.

Prasad, V., Vandross, A., Toomey, C., Cheung, M., Rho, J., Quinn, S., Chacko, S., Borkar, D., Gall, V., Selvaraj, S., Ho, N., \& Cifu, A. (2013). A decade of reversal: an analysis of 146 contradicted medical practices. Mayo Clinic Proceedings, 88(8), 790-798. doi: https://doi.org/10.1016/j.mayocp.2013.05.012.

Primrose, C., \& Primrose, W. (1992). Geriatric respite care--present practice and the potential for improvement. Health Bulletin, 50(5), 399-406.

Productivity Commission. (2008). Trends in aged care services: Some implications. Retrieved from http://www.pc.gov.au/ data/assets/pdf file/0004/83380/aged-care-trends.pdf (accessed Febuary 27, 2017).

Rai, G., Bielawska, C., Murphy, P., \& Wright, G. (1986). "Hazards for elderly people admitted for respite ("holiday admissions") and social care ("social admissions")." British Medical Journal (Clinical research ed.) 292(6515): 240-240.

Segall, N., Bonifacio, A., Schroeder, R., Barbeito, A., Rogers, D., Thornlow,D., Emery, J., Kellum, S., Wright, M., Mark, J., \& Durham VA. Patient Safety Centre of Inquiry. (2012). "Can we make postoperative patient handovers safer? A systematic review of the literature." Anesthesia \& Analgesia 115(1): 102-115.

Selley, C., \& Campbell, M. (1989). Relief care and risk of death in psychogeriatric patients. British Medical Journal, 298(6682), 1223. doi: https://doi.org/10.1136/bmj.298.6682.1223.

Box 1 Key questions to be tested in future research

\section{Research Question}

1. Are there any differences in the physical and mental health of RRC who die or have a major injury during the RRC admission compared to RRC residents who survived?

2. Are there any differences in outcomes of RRC residents compared to older people who remain at home? If so, what are the differences and why?

3. Are there any differences in outcomes of RRC residents compared to permanent nursing home residents? If so, does this remain after adjusting for the characteristics of the two populations? 
TABLE 1. Speculative model describing variables that may impact adverse outcomes associated with residential respite care.

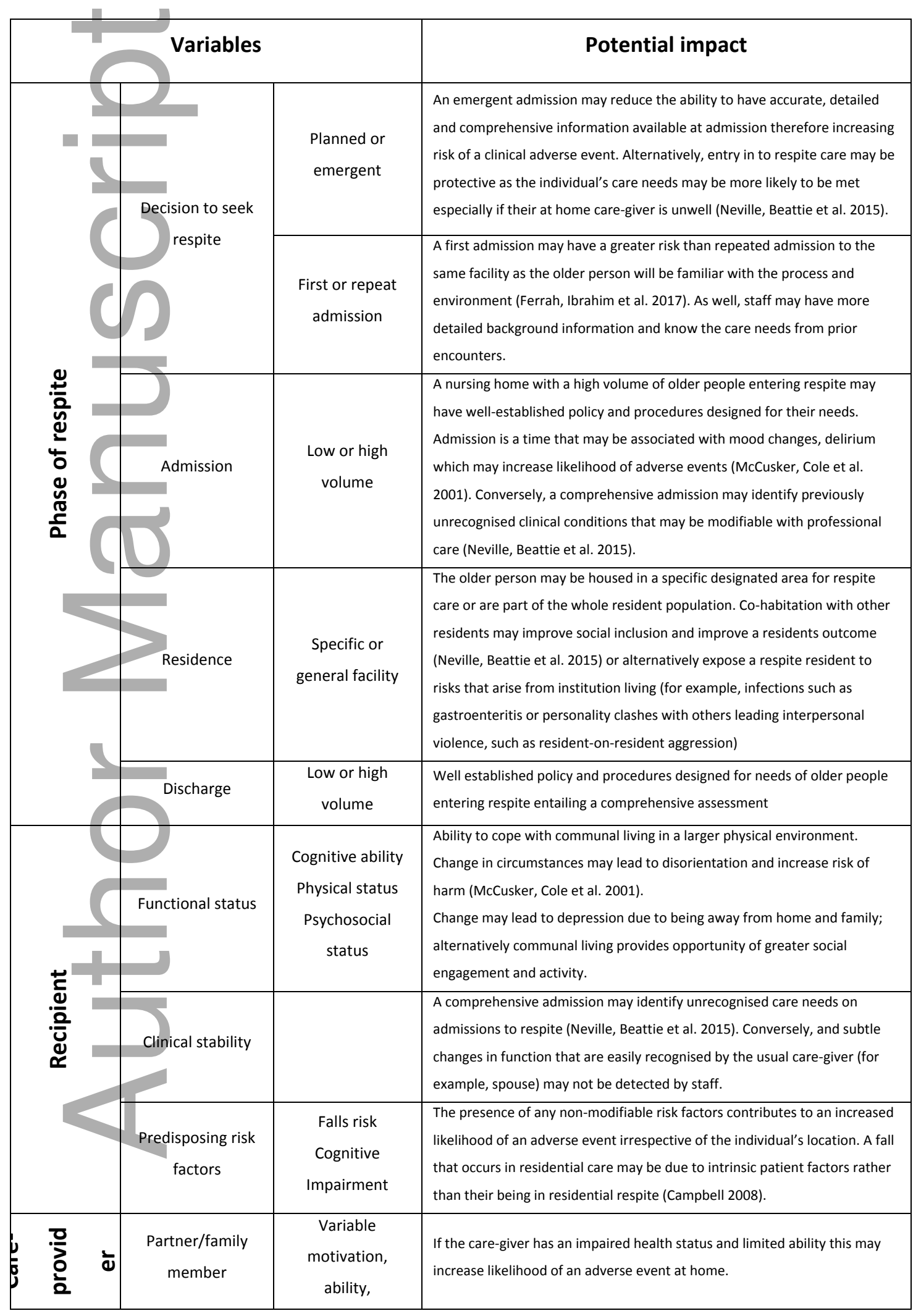




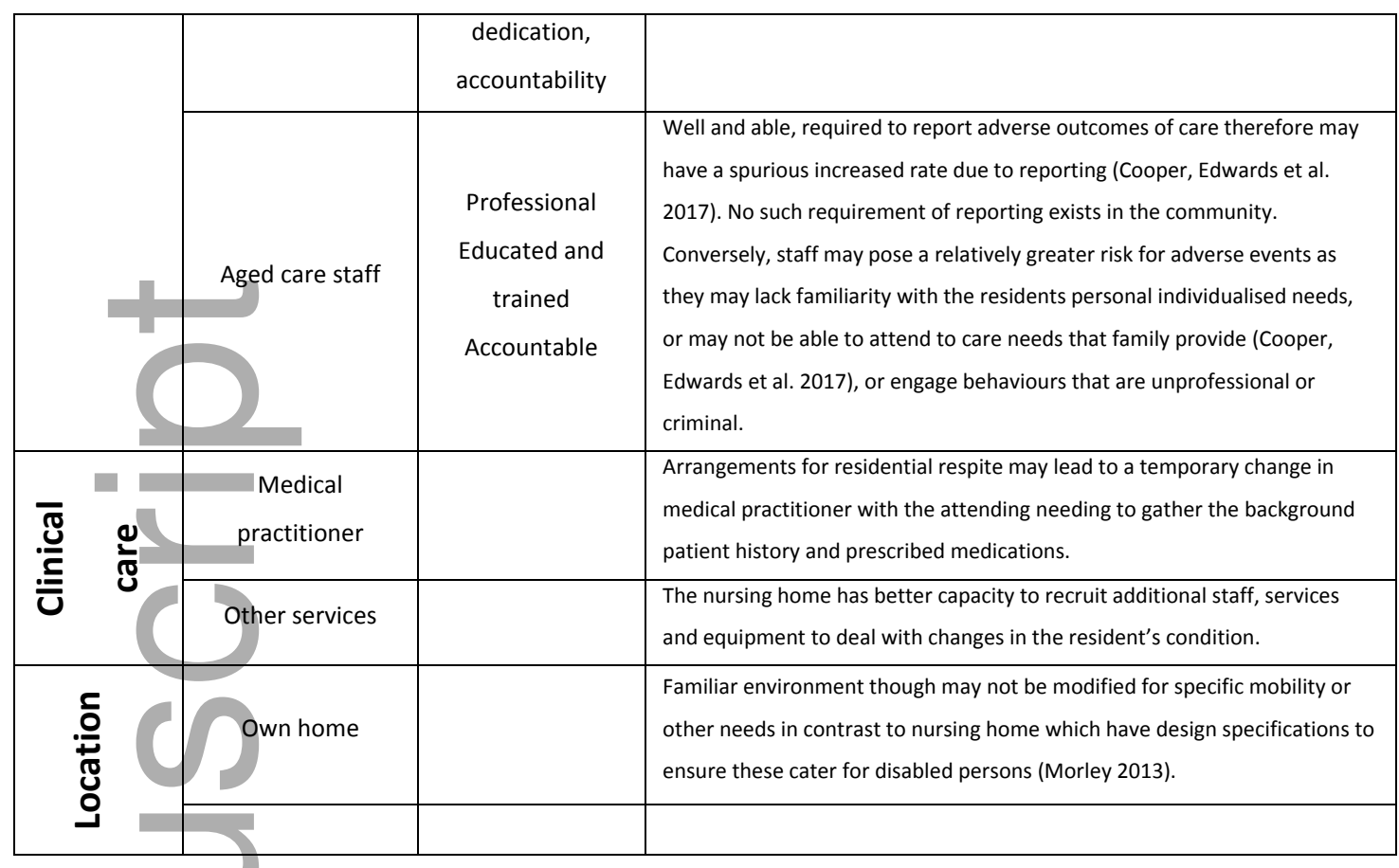

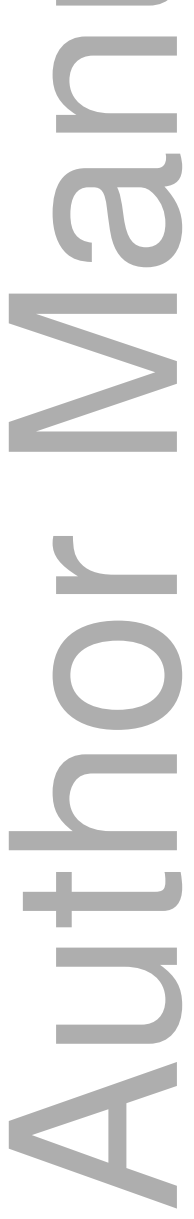




\section{APPENDICES}

\section{Appendix 1: Systematic Literature Review Method}

The authors conducted the following systematic literature review of published studies examining the deaths of older people during RRC to gain a deeper understanding of the current empirical evidence regarding the topic.

\section{Search Strategy}

The review was conducted in accordance with the Preferred Reporting Items for Systematic Reviews and Meta-Analysis (PRISMA) Statement (Moher, Liberati, Tetzlaff, \& Altman, 2009). The following databases were searched: Ovid (Medline), EMBASE, CINAHL, Cochrane Database of Systematic Reviews, PsychINFO, Web of Science and Scopus.

Three concepts were derived by researchers: "respite"; "nursing home"; and "death", and key terms were developed in consultation with a professional biomedical science librarian to produce a master list, which was adapted to and used to search each database.

Records were excluded if found to be duplicates, and pertained to in-home respite care. Records were also excluded if the publication type was an address, bibliography, biography, case report, comment, conference abstract, dissertation, thesis, editorial, festschrift, guideline, historical article, tutorial, interview, patient education handout or portrait.

\section{Inclusion Criteria}

Studies were included if they were original research generating empirical data and published in English, French, German, or Spanish in a peer-reviewed journal. The search was restricted to studies published between 1 January 1985 and 1 August 2015 to ensure it captured as much as possible contemporary respite practices. Studies were included if they examined a population of older adults admitted into a facility for respite care and mortality during and/or after a residential respite stay.

Selection of Studies and Risk of Bias

Results were screened for eligibility, initially by title and abstract, then by full text by one researcher. A bibliographic review of included articles was conducted to identify additional 
relevant studies. The final selection was made by consensus between researchers. The quality of the studies was assessed and made by agreement between researchers using the National Heart, Lung, and Blood Institute (NIH) assessment tool for observational and crosssectional studies (National Institute of Health, 2014).

As eligible studies were published prior to 2000, and to ensure no recent studies were missed, a second separate and independent search was conducted on 6 October 2015 by one researcher in Ovid, one of the most comprehensive medical databases (US National Library of Medicine, 2016). No additional eligible studies were found. Authors of the eligible studies, whose contact details could be found $(n=4)$ were also contacted to enquire about recent studies. There was no response at 12 months after request.

\section{Data Extraction}

Information on study and population characteristics such as aim, location, study design, follow up period, comparison group, age, gender, definition of respite, duration of respite, and outcomes of respite were extracted. Any ambiguities in studies were resolved by consensus of three researchers.

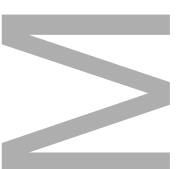

\section{Appendix 2: Systematic Literature Review Results}

The systematic literature review conducted by the authors revealed the following is known on deaths of older people during RRC.

\section{Study Characteristics}

The 12 included studies were predominantly from the United Kingdom, and published over a 12-year period with most conducted over 15 years ago. Ten studies examined mortality rates, impacts and outcomes of residents in respite, the remaining two examined mortality in a broader aim of describing respite care from a specific provider. In 11 of the 12 studies, follow-up after the initial admission to respite ranged from five (Primrose \& Primrose, 1992) to 55 (Rai et al., 1986) months. Six studies included comparison groups in other types care.

\section{Population Characteristics}


Population sizes were heterogeneous with the majority of studies $(n=8)$ comprising approximately 100 or less residents. Ten studies examined respite facilities in a hospital. Demographic characteristics were fairly consistent across studies, with a mean age of 70 to 80 years reported in eight studies (Cassidy \& Farquhar, 1995; Chang et al., 1992; Dunstan, 1989; Harper et al., 1988; McCaffrey et al., 1989; O'Mahony et al., 1990; Primrose \& Primrose, 1992; Rai et al., 1986). Four studies(Dunstan, 1989; Harper et al., 1988; Primrose \& Primrose, 1992; Rai et al., 1986) had equivalent numbers of men and women and only one study had an all-male population (Chang et al., 1992). Study populations differed in cognitive, functional and comorbid status, $20 \%(n=10)$ (Dunstan, 1989$)$ to $47 \%(n=7)$ (Chang et al., 1992) of residents were diagnosed with dementia and one study only included residents who had dementia (Patterson \& Compton, 1989). Activities of daily living (ADL) was also measured (Cassidy \& Farquhar, 1995; Chang et al., 1992; O'Mahony et al., 1990) with one study only including residents who needed assistance with their ADLs (O'Mahony et al., 1990).

Very limited, if any information was available on carers, who were predominantly immediate female family members (daughters and wives) (Dunstan, 1989; Harper et al., 1988; Primrose \& Primrose, 1992) with a mean age of 65 years (39 - 86) (Primrose \& Primrose, 1992). Only one study examined carers in detail examining their health, hours spent caring and their attitudes towards respite care (Primrose \& Primrose, 1992).

\section{Characteristics of Respite}

Whist there was not a standard definition for respite care, studies often differentiated between "planned" or "emergent" admissions. Mean duration of respite was often two weeks. Two studies (McCaffrey et al., 1989; O'Mahony et al., 1990), reported intermittent respite schemes involving a period at home followed by a set period in respite ranging from two weeks to one month. Episodic admissions to respite were most common, occurring in $57 \%(n=30)$ (Cassidy \& Farquhar, 1995) to $84 \%(n=71)$ (Harper et al., 1988) of residents. Only two studies reported specific numbers of residents who had two admissions ( $7 \%, n=$ $16 ; 13 \%, n=2$ ) (Harper et al., 1988; Patterson \& Compton, 1989) and three or more admissions ( $3 \% n=7 ; 4 \% n=3$ ) (Harper et al., 1988; Patterson \& Compton, 1989).

\section{Outcomes of Respite Care}


Four outcome measures describing the destinations after respite were reported: death; discharged home; moved into permanent care; and hospitalisation. The later three were recorded if they occurred immediately after respite and mortality was recorded at any time during and after respite as reported in the studies.

\section{Mortality}

All twelve studies examined mortality during respite admission, reporting proportions ranging from $1 \%(n=129, n=1)$ (Choi \& Liu, 1998; Harper et al., 1988) to 35\% ( $n=15)$ (Rai et al., 1986). Notably, 70\% $(n=14)$ (Patterson \& Compton, 1989) of deaths were reported as occurring in people admitted for the first time. Only two studies re-examined morality at ten $(56 \%, n=28)$ (Dunstan, 1989) and twelve months (26\%, $n=14)$ (Cassidy \& Farquhar, 1995) following respite admission, reporting higher proportions than during admission. Similarly, where intermittent respite schemes were examined (McCaffrey et al., 1989; O'Mahony et al., 1990), higher proportions of mortality were reported when individuals were discharged $(19 \%, n=12 ; 25 \%, n=6)$ than during admission to respite $(13 \%, n=8 ; 4 \%, n=1)$ respectively.

Eleven of the twelve studies reported their mortality rates were within an expected range for the study population. Many of these studies (Cassidy \& Farquhar, 1995; Dunstan, 1989; Harper et al., 1988; Howarth et al., 1990; McCaffrey et al., 1989; O'Mahony et al., 1990; Patterson \& Compton, 1989; Selley \& Campbell, 1989) only examined planned admissions, the study (Rai et al., 1986) which reported an excess in mortality examined both planned and emergent admissions. Higher mortality was found in emergent admissions $(35 \%, n=15)$ (Rai et al., 1986) than planned admissions $(13 \%, n=9)$ (Rai et al., 1986).

\section{Secondary Outcomes}

Three of four studies investigating discharge home found $80 \%(n=55)$ (Rai et al., 1986) to 93\% ( $n=49)$ (Cassidy \& Farquhar, 1995) of participants returned home after respite. Between 2\% $(n=1)$ (Rai et al., 1986) and 4\% $(n=3)$ (Harper et al., 1988) of participants were reported as being hospitalised during or after respite. Higher proportions of respite residents in nursing homes and hostels (Choi \& Liu, 1998) were discharged to permanent care than individuals in hospital-based respite. Only one study (Choi \& Liu, 1998) reported 
the number of respite admissions prior to moving to permanent care and found $33 \%$ ( $n=$ 5817) of residents transitioned after one admission.

\section{Causes and Manner of Death}

Only four studies (Howarth et al., 1990; McCaffrey et al., 1989; Patterson \& Compton, 1989;

Rai et al., 1986) reported the causes of death, not a single death due to injury was reported, all deaths were deemed natural with most being due to bronchopneumonia and heart disease. The process of determining cause of death was explicitly stated in only one study (McCaffrey et al., 1989) being death certification and hospital records. Five studies (Dunstan, 1989; Harper et al., 1988; Howarth et al., 1990; McCaffrey et al., 1989; O'Mahony et al., 1990) recorded the health status of respite residents, of these studies two (Dunstan, 1989; Harper et al., 1988) reported that on admission to respite, health status of residents who ultimately died did not differ from other residents. Where iatrogenic complications were considered (Chang et al., 1992; Rai et al., 1986), studies did not describe if complications had an effect on mortality. Studies also did not describe whether cause of death was related to an injury, a new illness or exacerbation of an existing illness.

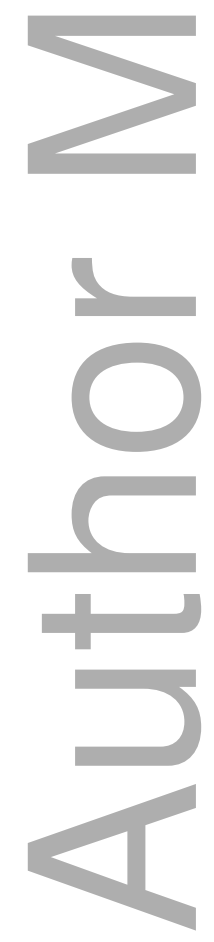


Appendix 3: Summary of Studies in the Systematic Literature Review.

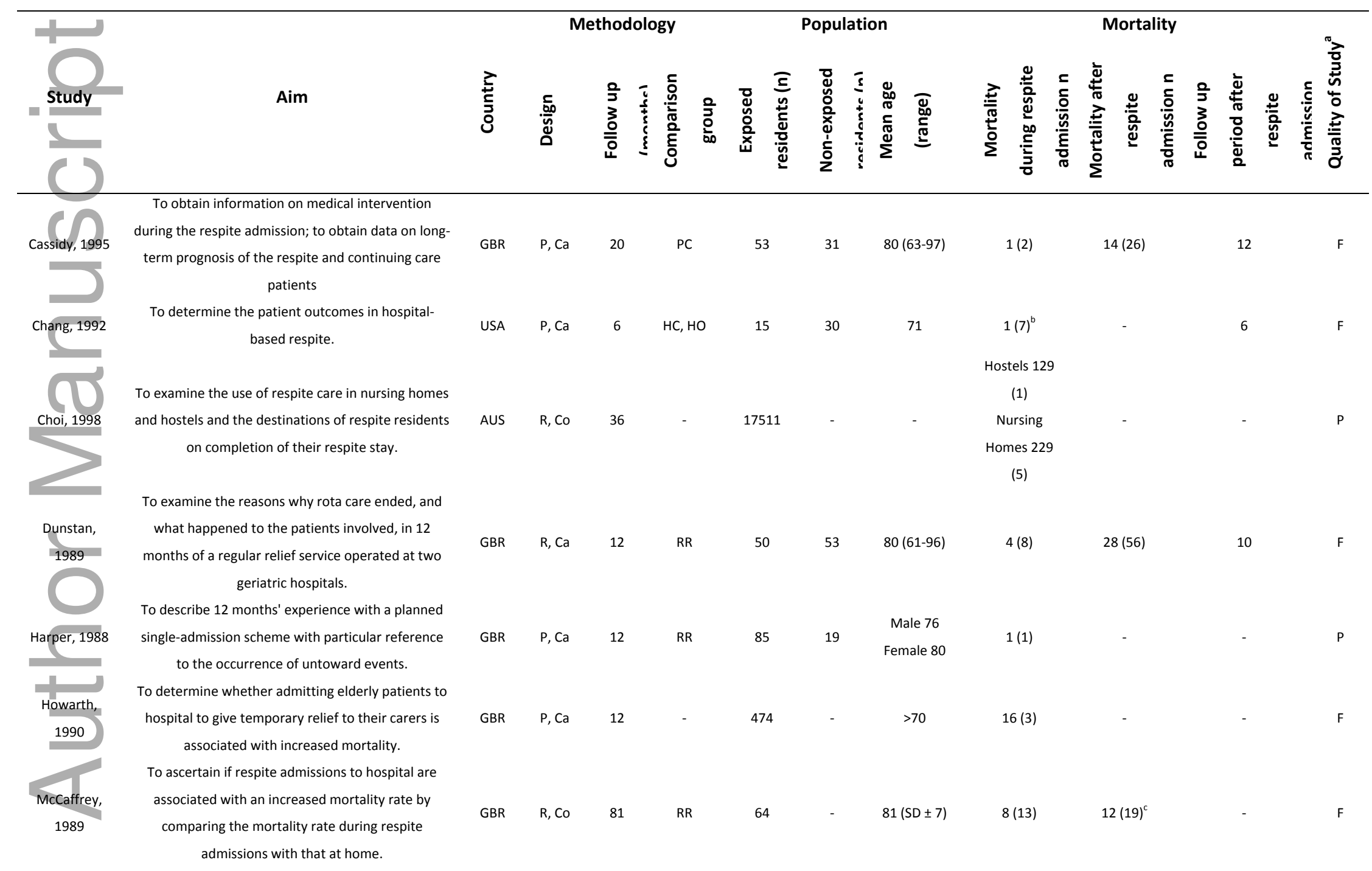

This article is protected by copyright. All rights reserved 


\begin{tabular}{|c|c|c|c|c|c|c|c|c|c|c|c|c|}
\hline $\begin{array}{l}\text { O'Mahony, } \\
1990\end{array}$ & $\begin{array}{l}\text { To describe our experience of an intermittent } \\
\text { respite scheme over the four year period 1984-88. }\end{array}$ & IRL & $\mathrm{R}, \mathrm{Co}$ & 44 & - & 24 & - & $77(\mathrm{SD} \pm 2)$ & $1(4)$ & $6(25)^{c}$ & - & $\mathrm{F}$ \\
\hline $\begin{array}{c}\text { Patterson, } \\
1989\end{array}$ & $\begin{array}{l}\text { To look at the mortality rates of patients admitted to } \\
\text { a purpose built psychogeriatric unit. }\end{array}$ & GBR & $\mathrm{R}, \mathrm{Co}$ & 22 & - & 243 & - & - & $20(8)$ & - & - & $\mathrm{F}$ \\
\hline $\begin{array}{r}\text { Prim } \\
19\end{array}$ & $\begin{array}{l}\text { To describe a medical audit examining the current } \\
\text { practice in relation to geriatric respite care } \\
\text { organised through the Department of Medicine for } \\
\text { the Elderly, Aberdeen }\end{array}$ & GBR & $\mathrm{P}, \mathrm{Co}$ & 5 & - & 87 & - & $80(63-92)$ & $2(2)$ & - & - & $P$ \\
\hline & $\begin{array}{l}\text { To look at the incidence of illness and death during } \\
\text { the first arranged admission for respite care. }\end{array}$ & GBR & $\mathrm{R}, \mathrm{Co}$ & 55 & - & $\begin{array}{l}\text { Planned } \\
\quad 69 \\
\text { Emergen } \\
\text { t } 43\end{array}$ & - & $\begin{array}{l}\text { Planned } 82 \\
(S D \pm 8) \\
\text { Emergent } 85 \\
(S D \pm 5)\end{array}$ & $\begin{array}{l}\text { Planned } 9 \\
\text { (13) } \\
\text { Emergent } 15 \\
\text { (35) }\end{array}$ & - & - & $\mathrm{P}$ \\
\hline Selley, 1989 & $\begin{array}{l}\text { Whether there was an increased risk of a patient } \\
\text { dying when admitted to the unit for relief care } \\
\text { compared with the risk for that patient at home or } \\
\text { elsewhere. }\end{array}$ & GBR & $\mathrm{R}, \mathrm{Ca}$ & 36 & $\mathrm{HC}$ & 210 & - & $>65$ & 19 (9) & 29(14) & - & $\mathrm{P}$ \\
\hline
\end{tabular}

Countries: USA = United States of America; AUS = Australia; GBR = United Kingdom of Great Britain and Northern Ireland; IRL = Ireland

Study design: $P=$ prospective; $R=$ retrospective; $\mathrm{Co}=$ cohort $\mathrm{Ca}=$ case-control

Comparison group: $\mathrm{HC}=$ home care, $\mathrm{PC}=$ permanent care, $\mathrm{RR}=$ other respite residents

a. Based on Quality Assessment Tool for Observational Cohort and Cross-Sectional Studies (National Institute of Health, 2014), ranging from "poor, fair, good".

b. Total number of deaths during and up to 6 months after respite stay

c. Deaths where residents on planned intermittent respite cycles were not in respite at time of death.

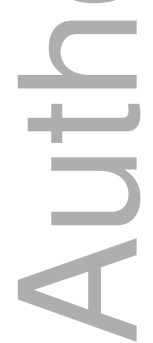

This article is protected by copyright. All rights reserved 


\section{University Library}

\section{- M M N E R VA A gateway to Melbourne's research publications}

Minerva Access is the Institutional Repository of The University of Melbourne

\section{Author/s:}

Willoughby, M;Ibrahim, JE;Ferrah, N;Bugeja, L

Title:

Optimising residential respite care in nursing homes: Current problems and solutions for a better future

\section{Date:}

2018-06-01

\section{Citation:}

Willoughby, M., Ibrahim, J. E., Ferrah, N. \& Bugeja, L. (2018). Optimising residential respite care in nursing homes: Current problems and solutions for a better future. INTERNATIONAL JOURNAL OF OLDER PEOPLE NURSING, 13 (2), https://doi.org/10.1111/opn.12180.

Persistent Link:

http://hdl.handle.net/11343/293912 